\title{
Capital mercantil, transportes fluviais e a rede urbana sub-regional de Parintins-AM
}

\section{Mercantile capital, fluvial transport and the sub-regional urban network of Parintins-AM}

\author{
Fernando Luis Farias da Silva ${ }^{A}$ \\ Estevan BARTOLI ${ }^{\mathrm{B}}$
}

${ }^{a}$ Graduado em Licenciatura em Geografia pela Universidade do Estado do Amazonas (UEA).

${ }^{\text {b }}$ Professor Doutor do curso de Licenciatura em Geografia na Universidade do Estado do Amazonas (UEA), campus Parintins, doutor em Geografia pela Universidade Estadual Paulista (Unesp).

O texto tem como objetivo analisar as atividades do Capital Mercantil em Parintins (AM), cujas práticas espaciais atingem diversas áreas circunvizinhas, formando a rede urbana a partir de transportes fluviais. A coleta de dados é relativa às sete maiores empresas comerciais locais que atuam na economia em múltiplas frentes, estruturando sistemas territoriais. Tais empresas realizam intensas redes de trocas de mercadorias com: 1) Manaus enquanto centro primaz; 2) a rede urbana do estado do Pará; 3) o entorno sub-regional cuja distribuição é feita por embarcações pertencentes à economia popular. Produzem alterações no espaço intraurbano de Parintins se apropriando de espaços públicos (beiras de rio) para construção de portos, além de novos investimentos nas periferias em expansão. Constata-se que as atividades desse Sistema Territorial dominante é uma das principais forças propulsoras de influência na formação da rede urbana sub-regional de Parintins, o que a torna um importante nódulo da região.

Palavras-chave: capital mercantil, sistemas territoriais, rede urbana, transporte fluvial.

This paper aims at analyzing the activities of the Mercantile Capital in Parintins, state of Amazonas, Brazil, whose spatial practices reach several surrounding areas, forming an urban network based on fluvial transportation. Data collection is related to the seven largest local commercial companies that operate in the economy on multiple fronts, structuring Territorial Systems. Such companies conduct intense product exchange networks with: 1) Manaus as a prime center; 2) an urban network in the state of Pará; 3) the sub-regional environment, whose distribution is made by vessels belonging to the popular economy. They produce changes in Parintins' intraurban space by appropriating public spaces (river borders) for the construction of ports and by investing in the expansion of peripheries. The activities of this dominant Territorial System are one of the main driving forces that influence the formation of the sub-regional urban network of Parintins, making it an important nodule of the region.

Keywords: mercantile capital, territorial systems, urban network, fluvial transport. 


\section{INTRODUÇÃO}

Este trabalho ${ }^{1}$ traz resultados de estudos sobre as atividades do Capital Mercantil e da rede urbana que está sob sua influência a partir da cidade de Parintins (AM). Considera-se a hipótese de que as empresas comerciais que pertencem a essa fração do Capital são as principais forças propulsoras que desempenham papel articulador na ligação entre a cidade e suas áreas de entorno, compondo a rede urbana sub-regional do baixo Amazonas ${ }^{2}$, colaborando para compreensão funcional e estrutural dessa rede primordialmente conectada por fluxos de transportes fluviais.

Da análise dos fluxos de transportes fluviais realizados pelas empresas pertencentes ao Capital Mercantil, bem como os fluxos de Parintins com a metrópole Manaus, se desdobram outros objetivos específicos: 1) cartografar e mapear fluxos e fixos mantidos pelas empresas comerciais; 2) elencar as diversas atividades que o capital mercantil manifesta, estruturando sistema territorial; 3) apontar as consequências das ações das empresas comerciais no espaço intraurbano de Parintins.

A metodologia empregada consiste na observação não-participativa, aplicação de questionários com perguntas abertas a uma amostra relativa às sete maiores empresas comerciais de Parintins, realizando coleta de dados secundários em instituições públicas e a consequente tabulação e elaboração de cartografia dos fluxos e fixos, com base nos resultados obtidos em campo. As informações coletadas ${ }^{3}$ originaram mapas e quadros que exprimem as redes e estratégias que as empresas comerciais adotam em suas práticas espaciais.

Os dados demonstram que há densidade de relações, qualificando Parintins como importante centro distribuidor de produtos industrializados, complementando recentes abordagens sobre suas funções enquanto

1 O texto apresenta resultados do projeto de Iniciação Científica realizado na Universidade do Estado do Amazonas, campus de Parintins, nos anos de 2017/2018.

2 Quando tratamos no presente texto do termo sub-regional, nos referimos à $9^{\mathrm{a}}$ sub-região do Baixo-Amazonas, instituída pela Constituição do Estado do Amazonas, sendo composta pelos municípios de Urucará, Boa Vista do Ramos, Barreirinha, São Sebastião do Uatumã, Nhamundá e Parintins - essa última classificada pelo IBGE como Centro Sub-Regional B (IBGE, 2007).

3 As coletas de dados foram realizadas de março a outubro de 2018. cidade média de responsabilidade territorial e enquanto fornecedora de serviços de saúde e educacionais (SCHOR; OLIVEIRA, 2016).

No primeiro subtítulo, abordamos redes urbanas e os papéis das cidades na Amazônia, levando em conta a difusão dos processos urbanos para além do espaço físico das cidades, discutindo a tese da urbanização extensiva (MONTE-MÓR, 2003), frisando as territorialidades que o Capital Mercantil mantém em Parintins e na sub-região por meio das ações das empresas comerciais, que articulam diferentes Sistemas Territoriais.

No segundo momento, tecemos reflexões teóricas que dão suporte para as discussões sobre as ações do Capital Mercantil em Parintins: definições, funcionalidades e estruturação. Essa fração se metamorfoseia em diferentes atividades para possibilitar sua manutenção de poder econômico. As empresas comerciais são consideradas parte deste processo, pelas características de suas atuações econômicas na cidade e na sub-região. Apresentamos dados sobre os fixos que as empresas possuem (imóveis, galpões, lojas, portos etc.) e mapas que demonstram as redes que essas empresas formam na sub-região, cuja abrangência espacial consta como importante fator para a reprodução do Capital Mercantil.

No último momento descrevemos as estratégias dessas empresas e os impactos causados na configuração do espaço intraurbano. São conflitos relacionados ao uso do espaço urbano que ocorrem em determinados pontos da cidade com maior intensidade em áreas conhecidas como "beiras de rio". Concluímos que através das formas do uso do solo urbano se estrutura um Sistema Territorial dominante, que é o principal propulsor da formação da rede urbana sub-regional, atingindo também cidades do oeste paraense.

\section{REDES URBANAS E SISTEMAS TERRITORIAIS}

Para Corrêa (2012, p. 200), as redes urbanas se definem pelo conjunto de localizações humanas articuladas entre si por meio de vias e fluxos. Corrêa (1997) ressalta ainda, nesta mesma linha de pensamento, que as redes, especialmente as urbanas, são um produto das relações entre indivíduos, historicamente contextualizados, e que tem como objetivo articular as sociedades numa dada porção do espaço por meio de interações sociais espacializadas, garantindo a sua existência e reprodução. Aponta que as cidades são os fixos, sendo "os vértices ou nós" (CORRÊA, 1997, p. 93) dotados de funções urbanas. Correspondem aos pontos dos quais os fluxos saem ou chegam. 
Ao fazer uma apreciação de uma rede na escala do intraurbano, podemos interpretar um fixo como um prédio público, um hospital, uma loja ou um porto, ou seja, um ponto onde convergem ou partem trajetos de pessoas ou meios de transporte. Os fluxos são as conexões que unem os centros que formam uma rede urbana, são os caminhos ou ligações entre esses centros. "Os fluxos no âmbito dessa rede são intensos e diferenciados, qualitativa e quantitativamente, envolvendo informações, capital, pessoas e mercadorias" (CORRÊA, 2012, p. 202).

Na classificação elaborada pelo IBGE (2007) sobre as Regiões de Influência das Cidades, Parintins é caracterizada como Centro sub-regional B. Segundo Schor et al. (2014) as classificações do IBGE para o entendimento da rede urbana no Amazonas são insuficientes para caracterizar a dinâmica de suas cidades, defendendo outras definições históricas, econômicas, sociais e funcionais para redefinir o estudo das formas e suas funções.

Para construção da tipologia proposta à rede urbana do estado do Amazonas, Oliveira e Schor (2009, 2010, 2011) criaram metodologia de análise a partir de tipologia que abarca parâmetros relacionais que incorporam dados socioeconômicos e demográficos, com aspectos de hidrologia, biogeografia, acesso aos recursos naturais e demais temas de interação sociedade-natureza. Delimitaram ainda alguns arranjos institucionais que poderiam ser analisados em conjunto, estabelecendo uma hierarquia urbana para essas cidades. Tais arranjos institucionais foram considerados como elementos fundamentais para a consolidação da rede urbana, variando de instituições de educação e saúde aos fluxos de mercadorias (SCHOR et al. 2014). Para os autores, Parintins passa a cumprir importante função pela presença de instituições na cidade, ressaltando o papel de mediação política, econômica, cultural e simbólica, que caracteriza sua responsabilidade territorial.

Dentro dessa perspectiva, a abordagem sobre as redes urbanas, mais especificamente as da Amazônia, pode ajudar a compreender o papel que as empresas comerciais analisadas cumprem nas ligações realizadas com o entorno, e principalmente a capacidade de ordenamento territorial que lhes confere vantagens nas disputas por mercados.

Contribuindo para análise de como esse processo urbano ocorre, é válida a noção de urbanização extensiva, definida como "urbanização que se estende para além das cidades em redes que penetram virtualmente todos os espaços regionais integrando-os em malhas mundiais" (MONTE-MÓR, 1994, p. 3).
Segundo Monte-Mór (2003, p. 89), essa urbanização que se estende pelo que ele chama de tecido urbano, ou seja, todo o espaço social que o urbano abrange, é a materialização de processos de produção e reprodução do capital que acabam por ser frutos do confronto do industrial com o urbano, sobrepondo essas relações socioespaciais e o processo urbano-industrial aos processos locais. $\mathrm{O}$ autor salienta que esse processo leva junto consigo as organizações políticas próprias da cidade seja às periferias, regiões metropolitanas ou localidades remotas -, desencadeando a politização de todo o espaço social. Assim, esse fenômeno de expansão inclui além do que o urbano produz materialmente, como produtos industrializados e processos políticos e/ou culturais.

A urbanização extensiva, portanto, enquanto fenômeno que se dá a partir das cidades avançando para outros pontos do espaço geográfico, carrega formas e processos inerentes ao capital. Fornece base para analisar as estratégias e meios que as empresas comerciais de Parintins usam para atingir os pontos cada vez mais longínquos do nó (cidade).

Ao tecido urbano, são necessários meios de circulação para que a capacidade de influência se efetive. Os transportes, nesse caso, se tornam um dos fatores fundamentais a essa concretização, que permitem ao capitalismo - força imbricada ao urbano - a "anulação do espaço pelo tempo” (MARX apud HARVEY, 2005, p. 145), permitindo a ele conquistar territórios e implantar novas territorialidades de domínio.

As redes locais das empresas comerciais necessitam estabelecer fluxos através da navegação, que se torna uma estratégia para obterem vantagens comerciais, instituindo relações de poder, conformando-se um Sistema Territorial.

A partir dessas discussões é preciso entender que as empresas estudadas fazem parte da fração relativa ao Capital Mercantil, explorando mão de obra local e privatizando espaços públicos. Criam, assim, redes locais e sub-regionais, necessitando moldar o espaço urbano cujas frações são interpretadas enquanto nós multireticulares, pressionando áreas estratégicas, como as beiras de rios, por exemplo.

Dentre os estudos acerca da análise das territorialidades em cidades com intensa dinâmica ribeirinha, Bartoli (2017) propõe a existência do Sistema Territorial Urbano-Ribeirinho (STUR), ligado à economia popular urbana e que realiza mediação entre as áreas de entorno da cidade. Tem papel dual e de complementaridade, uma vez que serve tanto à economia popular quanto às atividades voltadas ao Capital Mercantil dominante. 
O STUR está intensamente ligado ao Sistema Territorial Urbano-Fluvial (STUF), composto pelo capital mercantil de Parintins - que é realizado por via fluvial - e que tem como os principais sujeitos os empresários proprietários dos grupos comerciais locais (BARTOLI, 2018a).

O STUF é um Sistema Territorial que "cada vez mais se sobrepõe e absorve as dinâmicas ribeirinhas", principalmente aquelas relacionadas ao "uso do solo urbano beira-rio" (BARTOLI, 2017, p. 93). Discorrendo sobre as funcionalidades desse sistema, Bartoli (2018a) afirma que o STUF não considera os rios como espaços intencionais para vínculos simbólico e/ou culturais, ou ainda como espaço de subsistência, fazendo o uso destes apenas como meio para a circulação de mercadorias em escalas diferenciadas, principalmente com a metrópole Manaus, sempre tendo uma conexão bastante intensa com o Capital Mercantil, que lhe fornece meios para suas articulações.

A figura 1, elaborada por Bartoli (2017), demonstra como os dois sistemas territoriais estão estruturados e complementam-se através dos seus modos de atuação, bem como os conflitos existentes no entrelaçamento desses sistemas, onde a cidade se apresenta como ambiente mediador. Atingem ainda áreas longínquas de baixa interação com a cidade.

Figura 1 - Conexões entre os sistemas territoriais mediados por redes de sujeitos na cidade.

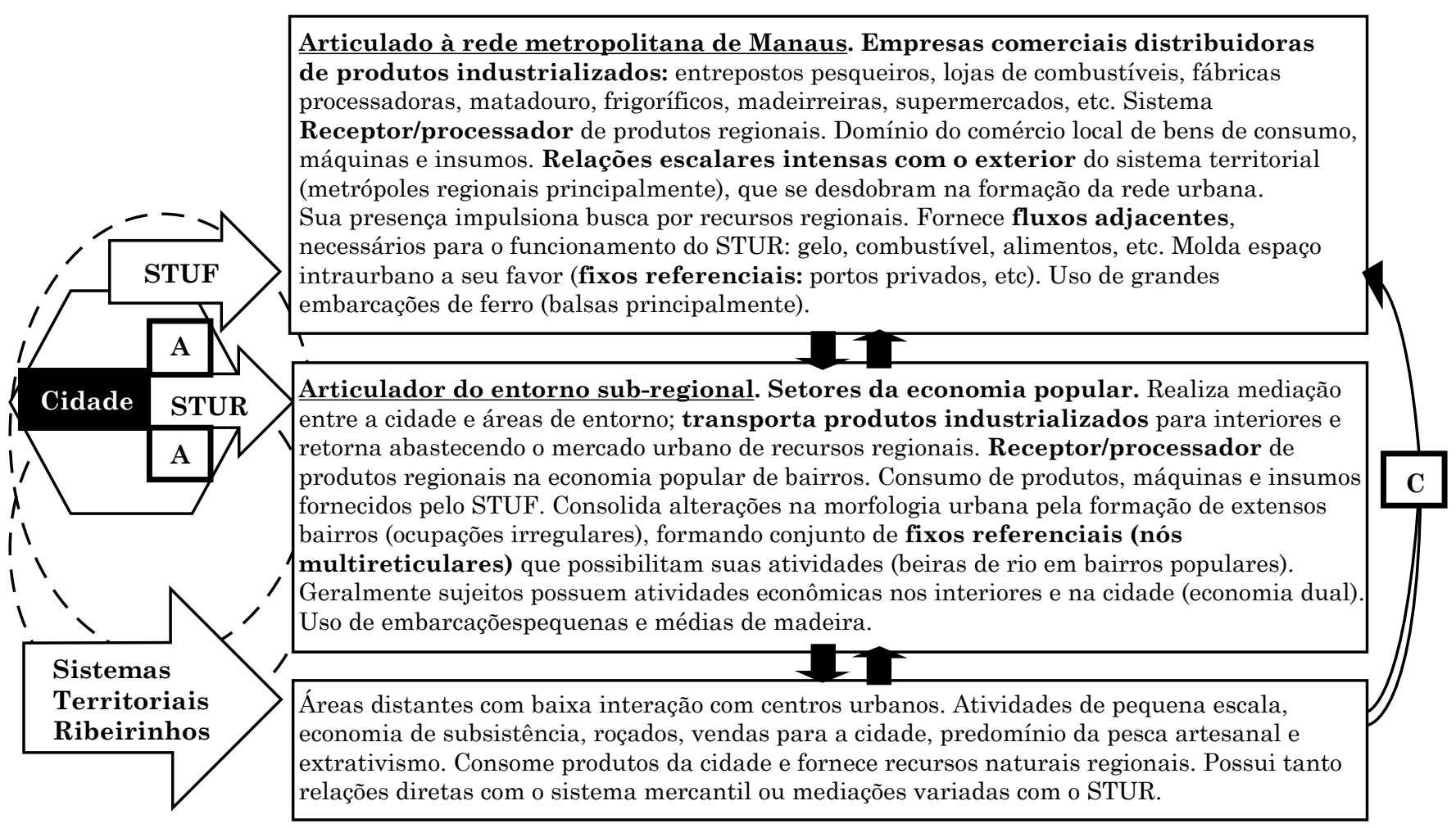

LEGENDA: A - Tensões e conflitos: produção do espaço urbano (ênfase nas beiras de rio); B - Hibridização: elaboração de soluções criativas e adaptações técnicas em instrumentos de trabalho, moradia, tipos de embarcações e ouras formas espaciais perceptíveis em bairros populares; $\mathrm{C}$ - extração de recursos regionais (inclusive areia e seixo para construção civil) realizada por grandes empresas comerciais da cidade; não há mediações ou processamento, mantendo sujeitos populares que abastecem tal fluxo em grau elevado de territorialidade passiva.

Fonte: Bartoli (2017).

No item seguinte, demonstraremos as áreas de abrangência das empresas pertencentes ao STUF. Essas áreas são atingidas pelo que Bartoli (2018a) denomina como "força centrífuga" (cidade - interiores), ou seja, a cidade possibilita bases de ação para que sujeitos atinjam localidades distantes da cidade realizando a distribuição de produtos industrializados, corroborando a tese da urbanização extensiva. $\mathrm{O}$ autor ressalta que são os sujeitos pertencentes ao Sistema Territorial Urbano-Ribeirinho (economia popular) os principais responsáveis pela distribuição de produtos 
para as áreas de entorno. O STUR é impulsionado pela demanda do STUF, que ainda fornece base para que as embarcações populares circulem às longínquas calhas de rios, fornecendo gelo, gasolina, produtos industrializados, entre outros, como descreve a figura 1. Portanto, as empresas comerciais do STUF necessitam e se beneficiam parcialmente da navegação popular.

Já a "força centrípeta" (interiores - cidade) são os fluxos constantes de redes de sujeitos diversos para a cidade em busca de bens e serviços, acesso institucional, saúde, educação, mercados e outros (BARTOLI, 2018a).

\section{As EMPRESAS COMERCIAIS E O CAPITAL MERCANTIL EM PARINTINS}

As empresas comerciais se estabeleceram comercialmente na cidade e estendem seus domínios para a sub-região através do comércio varejista e atacadista de uma infinidade de produtos industrializados, que vão desde materiais de construção civil até combustíveis.

Uma das características dessas empresas é a variedade de atividades que exercem, pertencendo à fração do Capital Mercantil. Para Cano (2010), essa fração pode compreender as formas comercial e usurária, tendo sua origem antes da etapa de acumulação primitiva quando se iniciaram as trocas mercantis, ou seja, antes do Capital Industrial. Porém, segundo o autor, com o capitalismo, a forma inicial não se perde, mas algumas de suas frações transformam-se em Capital Produtivo ou subordinam-se ao Capital Industrial e as outras partes assumem outras funções como o Capital Imobiliário, por exemplo (CANO, 2010).

O Capital Mercantil em Parintins veio se consolidando através de ciclos econômicos, principalmente do extrativismo vegetal do pau rosa e do cultivo da juta, utilizando e explorando mão de obra barata nas suas atividades, hoje presente na extração de madeira, areia e atividades da pesca industrial que abastecem lojas, madeireiras e frigoríficos (STUF explorando o STUR) (BARTOLI, 2018a).

Bresser-Pereira (1989), em análise da crise política brasileira na década de 1980, aprofundando estudos sobre o Capital Mercantil e Capital Industrial através da ótica de Caio Prado Júnior, atribui a Marx a denominação destas duas categorias - o Capital Mercantil fundamenta-se primordialmente na especulação, compra e venda de produtos e mercadorias a um preço que não condiz com o seu valor-trabalho, ou seja, compra-se barato e vende-se caro.
Numa perspectiva mais ampla, seria próprio do Capitalismo Mercantil o controle sobre o financiamento, domínio da produção local, armazenagem ou distribuição de mercadorias ou até mesmo o controle sobre o aparelho do Estado, que atua localmente (CANO, 2010).

Não se trata do Capital Mercantil tradicional, com modos de atuação que podem ser considerados primitivos, que mostra certa resistência em absorver novos métodos e técnicas à sua estrutura como o emprego de maquinário moderno e novas configurações de gestão. Ao se modernizar, o Capital Mercantil aumenta sua produtividade e se modifica de um modo funcional arcaico para o capital produtivo. Sobre essa questão, Bresser-Pereira (1982) afirma que "quando a produtividade ou a incorporação de progresso técnico tornam-se atividades dominantes, seu capital passa a ser industrial ou produtivo, ao invés de especulativo ou mercantil" (BRESSER-PEREIRA, 1982, p. 271).

Questionamos esse caráter produtivo, pois há variada pulverização dos investimentos do capital mercantil, que em constante metamorfose se adapta a diversas circunstâncias e cenários. No caso de Parintins, tais esferas também se aproveitam do boom gerado pelo sucesso do Festival Folclórico, se inserindo em atividades hoteleiras, redes de supermercados, agências de turismo, empresas de locação de equipamentos de som e iluminação etc.

Para Cano (2010), há uma metamorfose do capital mercantil antigo nas cidades para novas roupagens. São novas redes atacadistas, hotéis e supermercados, geralmente ocupados pelos descendentes de famílias tradicionais da região. São formas de capital que, muitas vezes, se transformam em capital industrial e bancários ou de financiamento, mas sempre garantem sua participação no poder local de forma reacionária.

Sua presença no meio rural é conhecida pelas grandes fazendas. Mesmo assim, possuem sede privilegiada no meio urbano para organizar outras atividades, como especulação fundiária e imobiliária, sempre investindo em novas frentes de acumulação ${ }^{4}$. No contexto de Parintins, tal setor se beneficia de exploração de recursos regionais

4 Em Parintins, os maiores produtores de gado são hoje os que mais investem no setor imobiliário local. O primeiro edifício residencial da cidade tem como proprietário um dos grandes fazendeiros. Um dos pecuaristas e dono de loja de materiais de construção entrevistado afirmou que o lucro do gado é cada vez menor e que hoje prefere investir no setor imobiliário. Casas em diversos bairros da cidade são construídas e vendidas com auxílio de financiamentos de Programas Federais. 
e conta com o trabalho disponível tanto nos interiores, quanto na cidade.

A partir dessa abordagem é que surgem elementos para análise das múltiplas frentes que as empresas comerciais atuam em uma cidade com forte dinâmica ribeirinha (caso de Parintins), onde especificamente um desses aspectos refere-se aos transportes fluviais realizados pelo STUF e o STUR.

As empresas estudadas, além de pertencerem originalmente ao ramo comercial, destacam-se também por atuações em outros ramos da economia local, como a pecuária, hotelaria, locação de imóveis residenciais e comerciais, locação de automóveis, locação de embarcações de transporte de cargas pesadas e até mesmo influenciando no setor político do município.

O domínio da navegação comercial na região por essas empresas pode ser considerado um dos pontos basilares para os negócios, uma vez que, para o Capital Mercantil, a circulação de mercadorias é primordial para sua reprodução.

Assim, as empresas comerciais analisadas são importantes distribuidoras varejistas - primordialmente por via fluvial - da cidade de Parintins: Grupo Baranda, Grupo Brito, Alírio Ferragens, Grupo Natal e Grupo Chiquinho, Grupo Brasileiro e Grupo Oliveira, destacam-se pela relativa solidez econômica e comercial dentro e fora do município.

De maneira geral, Parintins se destaca na sub-região como centro de distribuição de produtos industrializados. Influi diretamente nas localidades que se encontram abaixo na hierarquia urbana, tendo o REGIC/IBGE (2007) classificado a cidade como centro sub-regional de categoria $\mathrm{B}$, por possuir, segundo a metodologia dessa classificação, 71 relacionamentos com os outros centros urbanos que fazem parte da sua rede urbana.

A situação de Parintins é um fator favorável às atividades dessas empresas comerciais, pois possibilita a efetivação de redes e o emprego de técnicas que permite a concretização de relações econômicas das mesmas. Segundo Damiani, situação refere-se a "um espaço geográfico relativizado que se molda em função das técnicas, das estruturas econômicas e sociais e dos sistemas de relações" (DAMIANI, 2006 apud BARTOLI, 2017, p. 60). Assim, as atividades pertencentes ao STUF, que incentivam maiores deslocamentos dos sujeitos que pertencem ao STUR, nos auxiliam no entendimento do contexto situacional que o nó urbano possui. A posição estratégica da sede municipal, com plano urbano com acesso ao rio Amazonas e estando na rota entre as duas metrópoles regionais (Belém e Manaus), é outro fator que amplia a dinâmica.

As atuações das empresas são pautadas em combinações escalares da sub-região de Parintins com a metrópole Manaus e escalas mais amplas. Como aponta Bartoli (2017), a relação STUF/STUR estabelece elos mediadores necessários para que produtos de empresas globais sejam distribuídos na rede urbana do baixo Amazonas. Este afirma ainda que existe uma diferença na maneira em que esses dois tipos de fluxos se dão, a partir da tipologia das embarcações que os efetivam (BARTOLI, 2017).

No quadro 1 estão destacados os fixos, que correspondem aos imóveis e propriedades que pertencem às empresas estudadas e as principais mercadorias comercializadas na rede urbana.

Os fixos representam trunfos obtidos pelas empresas, configurando pontos estratégicos para concretizar as redes estabelecidas, indicando ainda que ambos se concretizam na formação de redes e escalas com cidades maiores e no espaço sub-regional.

O grupo que concentra maior estrutura e mantêm mais fixos obtém maior influência na formação das redes sub-regionais, como é o caso do Grupo Chiquinho que possui 15 imóveis, se destacando no ramo de combustíveis, peças automotivas, distribuição de gás de cozinha e água mineral, uma série de atividades no setor imobiliário (locações comerciais e residenciais) e locação de veículos. Atua também realizando empréstimos financeiros em troca até mesmo de imóveis como garantia no negócio, prática típica do capital mercantil. O grupo atua em setor que à primeira vista não parece ser de sua alçada, como o ramo da educação, construindo a recente Unidade da Fametro - Faculdade Metropolitana de Parintins (instituição particular de ensino superior). Através destas ações é que ficam claras as múltiplas estratégias visando à diversificação de área de atuação para a manutenção de poder comercial (CANO, 2010). 
Silva, F. L. F. \& Bartoli, E.

Quadro 1 - Número total de imóveis para cada empresa e mercadorias mais vendidas em Parintins e na sua Sub-região.

\begin{tabular}{|c|c|c|c|c|c|c|c|}
\hline Grupos & Baranda & Brito & Alírio & Natal & Chiquinho & Brasileiro & Oliveira \\
\hline $\begin{array}{l}\text { Número total de } \\
\text { imóveis }\end{array}$ & 07 & 05 & 03 & 08 & 15 & 12 & 7 \\
\hline Portos particulares & 1 & - & - & 2 & 1 & - & - \\
\hline Galpões & 2 & 1 & 1 & 1 & 2 & 2 & - \\
\hline Lojas & 3 & 4 & $2^{*}$ & 3 & 2 & 2 & - \\
\hline $\begin{array}{l}\text { Postos de } \\
\text { combustíveis/ } \\
\text { Postos Flutuantes }\end{array}$ & - & - & - & - & 5 & $8^{* *}$ & $7 * * *$ \\
\hline $\begin{array}{l}\text { Postos de venda de } \\
\text { gás de cozinha }\end{array}$ & 1 & - & - & 2 & 5 & - & - \\
\hline $\begin{array}{l}\text { Mercadorias } \\
\text { mais distribuídas } \\
\text { em Parintins e/ } \\
\text { ou na sub-região } \\
\text { pelas empresas } \\
\text { comerciais }\end{array}$ & $\begin{array}{l}\text { Cimento, } \\
\text { seixo, } \\
\text { areia, ferro }\end{array}$ & $\begin{array}{l}\text { Cerâmica, } \\
\text { telha, vaso } \\
\text { sanitário }\end{array}$ & $\begin{array}{l}\text { Ferragens, } \\
\text { tintas, } \\
\text { materiais, } \\
\text { elétricos }\end{array}$ & $\begin{array}{l}\text { Cimento, } \\
\text { tijolo, } \\
\text { ferro, gás } \\
\text { de cozinha, } \\
\text { água } \\
\text { mineral }\end{array}$ & $\begin{array}{l}\text { Gás de cozinha, } \\
\text { cimento, areia, } \\
\text { ferro, seixo, } \\
\text { material hidráulico, } \\
\text { moto peças, tintas, } \\
\text { automotivas, } \\
\text { baterias } \\
\text { automotivas, óleos } \\
\text { lubrificantes, } \\
\text { combustíveis }\end{array}$ & $\begin{array}{l}\text { Cesta básica, } \\
\text { Açúcar; } \\
\text { feijão; óleo } \\
\text { de soja, } \\
\text { produtos } \\
\text { de limpeza, } \\
\text { frios (carnes, } \\
\text { frango, e } \\
\text { outros), } \\
\text { combustíveis }\end{array}$ & Combustíveis \\
\hline \multicolumn{8}{|c|}{$\begin{array}{l}\text { NOTA: * } 1 \text { em Terra Santa (PA) } \\
* * 1 \text { em Terra Santa (PA), } 1 \text { em Juruti (PA) e } 1 \text { em Vila Amazônia - Parintins } \\
* * * 1 \text { em Nhamundá e } 1 \text { em Terra Santa (PA) }\end{array}$} \\
\hline
\end{tabular}

Fonte: Pesquisa de campo (SILVA, 2018).

A empresa possui ainda ligação com o poder público municipal por meio de aluguel de imóveis que abrigam instituições públicas e fornecimento de combustíveis para automóveis de instituições do Governo Federal em Parintins. A proximidade com as redes de poder locais torna tais grupos ainda mais fortes, o que deixa lacunas para estudos futuros sobre a centralidade política de Parintins enquanto cidade média de responsabilidade territorial (SCHOR; OLIVEIRA, 2016). O investimento do grupo no setor de transporte fluvial é intenso, obtendo vantagem no setor de navegação entre Manaus e Parintins por possuir 5 balsas de ferro com alta capacidade de transporte de carga, abastecendo empreendimentos da cidade.

O Grupo Baranda é a empresa comercial que atua no ramo de materiais para construção civil, gás de cozinha, água mineral e gêneros alimentícios e que articula uma diversidade de fixos. Possui um dos maiores supermercado da cidade que conta com estrutura melhor com relação aos concorrentes. Dispõe de maior diversidade de produtos e gêneros alimentícios e está localizado na principal avenida da cidade, exercendo centralidade por contar com galpões de armazenamento e distribuição de gás, água mineral e estiva. Pela proximidade dos seus principais portos, facilita o tempo de armazenagem e distribuição dos produtos.

Possui ainda a maior loja de materiais para a construção civil da cidade, atuando ainda no setor hoteleiro e de entretenimento, com imóveis localizados às margens do Lago Macurany, realizando eventos festivos em determinadas datas do ano, atuando na hospedagem de pessoas que possuem maior poder econômico e que alugam esses espaços na época do Festival Folclórico de Parintins, que acontece todo ano no último final de semana do mês de junho.

$\mathrm{Na}$ política local esse grupo exerce influência em articulações político-partidárias eleitorais em escala local e sub-regional, com intensas ligações políticas com a capital do estado, além de possuir forte influência em uma das agremiações folclóricas, o boi-bumbá Caprichoso. 
As agremiações têm sido alvos de disputas políticas acirradas entre os setores dominantes da cidade, almejando controle (através da eleição de presidentes das agremiações folclóricas) devido à enorme visibilidade que possuem, e manejo de vultosas cifras na realização do espetáculo, que é de grande porte.

É uma das empresas comerciais mais antigas da cidade, que cresceu pela intensa ligação com Manaus, utilizando 3 balsas que trazem seus insumos e mercadorias.

Destaca-se também o Grupo Natal, cujas atividades são mais voltadas ao comércio de materiais para a construção civil, distribuição de gás de cozinha e água mineral, se diferenciando dos grupos anteriores que apresentam maior diversidade de atuações. Esta empresa também adota o modal de transporte fluvial por meio de balsas, fundamentais na vantagem concorrencial para diminuição de custos na realização de sobrelucros, como nos grupos Chiquinho e Baranda.

Já o Grupo Brasileiro se destaca por possuir dois grandes supermercados e comércio de combustíveis, possuindo 8 postos de gasolina. Vem expandindo este ramo para cidades da sub-região de Parintins e ao oeste do estado do Pará, como mostra o quadro 1.

Algumas de suas filiais atualmente foram inseridas em bairros oriundos de ocupações irregulares nas duas últimas décadas, formando novas centralidades em eixos recentes de valorização. Isso resulta da rápida propagação e explosão de vendas de motocicletas na cidade, beneficiando esse tipo de investimento.

Das empresas estudadas, é a única a estabelecer ligação fluvial com a cidade de Santarém, abastecendo Parintins com produtos alimentícios para seus supermercados. Porém, Manaus ainda figura como seu principal centro fornecedor.

Assim como as demais empresas, utiliza balsas de ferro no transporte de mercadorias e de combustíveis. Associou-se à rede de distribuição Smart Supermercados, que tem gerado enorme concorrência com o supermercado Baranda. Isso indica como grupos locais passam a sofrer cada vez mais influência de grupos empresariais de fora da cidade. A instalação das Lojas Americanas (uma das maiores redes de lojas de departamentos do Brasil) em Parintins, em 2018, causou enorme desconforto aos empresários locais, acostumados à falta de concorrência.

O grupo Oliveira talvez seja o mais novo no mercado local e sub-regional. Tem como ponto econômico principal a atuação no ramo de distribuição de combustíveis. Sua rápida expansão permitiu a criação de uma rede de postos de combustíveis que atua tanto na cidade de
Parintins quanto na sub-região de influência. Com forte ligação com Manaus através de balsas de combustíveis, tem filial em Terra Santa, no extremo oeste do estado do Pará. A concorrência com demais grupos leva à maior articulação de investimentos comercias na sub-região. O grupo ainda não direcionou investimentos a outros setores, como é praxe do capital mercantil.

Os outros dois grupos empresariais de menor porte e em ascensão são os grupos Brito e Alírio Ferragens. Atuam majoritariamente no ramo do comércio de materiais para a construção civil, embora o Grupo Brito possua investimento em uma academia de ginástica e musculação. A concorrência levou o grupo Alírio Ferragens a instalar loja filial na cidade de Terra Santa no Pará. Tal fato mostra o interesse de expansão comercial de empresas para além de seu centro de gestão principal. Por não possuírem balsas próprias, esses dois grupos acabam dependendo da locação de balsas dos grupos concorrentes ou locação dos barcos de linha para o transporte de suas cargas.

As grandes balsas de ferro e empurradores são de alto custo de aquisição e manutenção. $\mathrm{O}$ uso desse tipo embarcação gera necessidade da construção de portos rústicos nas "beiras de rio" pelas empresas, causando conflito em locais antes públicos, agora restritos ao Capital Mercantil.

As balsas estabelecem rede no trecho Manaus/ Parintins, onde a metrópole é o principal centro fornecedor de produtos industrializados para as empresas comerciais, distribuindo gêneros alimentícios, combustíveis, areia, seixo, ferro, cimento, tintas, materiais elétricos e hidráulicos, peças, automotivas entre outros - e entre Santarém e Parintins. Apesar de citada apenas uma vez na pesquisa, Santarém (PA) aparece como centro fornecedor secundário que distribui apenas carregamentos de feijão ao supermercado do Grupo Brasileiro.

As empresas que não dispõem de tal vantagem para o transporte de cargas, ou fretam balsas dos grupos que possuem, tornando-se "reféns" dos preços do frete, ou utilizam os chamados "barcos de linha", também conhecidos localmente como "navios" de estrutura de ferro. Tais embarcações de ferro realizam transporte de cargas de menor volume de maior valor agregado, como fios elétricos, materiais de hidráulica e itens de maior valor vendidos em supermercados.

Outro atributo importante da rede urbana que as empresas formam corresponde aos diversos nós urbanos secundários formados por agrovilas e distritos, que funcionam como centros para redistribuição de produtos para as demais comunidades adjacentes e as mais distantes. 
Entre elas estão as agrovilas do Mocambo e Caburí, Vila Amazônia e comunidade do Bom Socorro do Zé Açú (todas pertencentes a Parintins). Por serem locais dotados de maior estrutura física e populacional do interior do município, tornam-se consumidoras em maior quantidade de produtos das empresas comerciais (SILVA, 2018). As mercadorias mais consumidas por essas localidades são materiais para a construção civil e gêneros alimentícios.

Os combustíveis são transportados para as Agrovilas através de barcos rústicos de madeira adaptados com tanques, chamados regionalmente de "charutos". O mapa 1 (Figura 2) demonstra o papel que Parintins exerce sobre essas áreas de entorno, reafirmando que a cidade distribui bens de consumo através das empresas comerciais exercendo força centrífuga (como apoio das embarcações populares do STUR). Além dos fluxos de distribuição, acontecem fluxos contrários que convergem em direção à cidade (força centrípeta), por consequência da presença de instituições de ensino, saúde e administrativos, corroborando o que afirma Bartoli (2018a).

Figura 2 - Nódulos secundários no interior do município de Parintins sob influência das empresas comerciais.

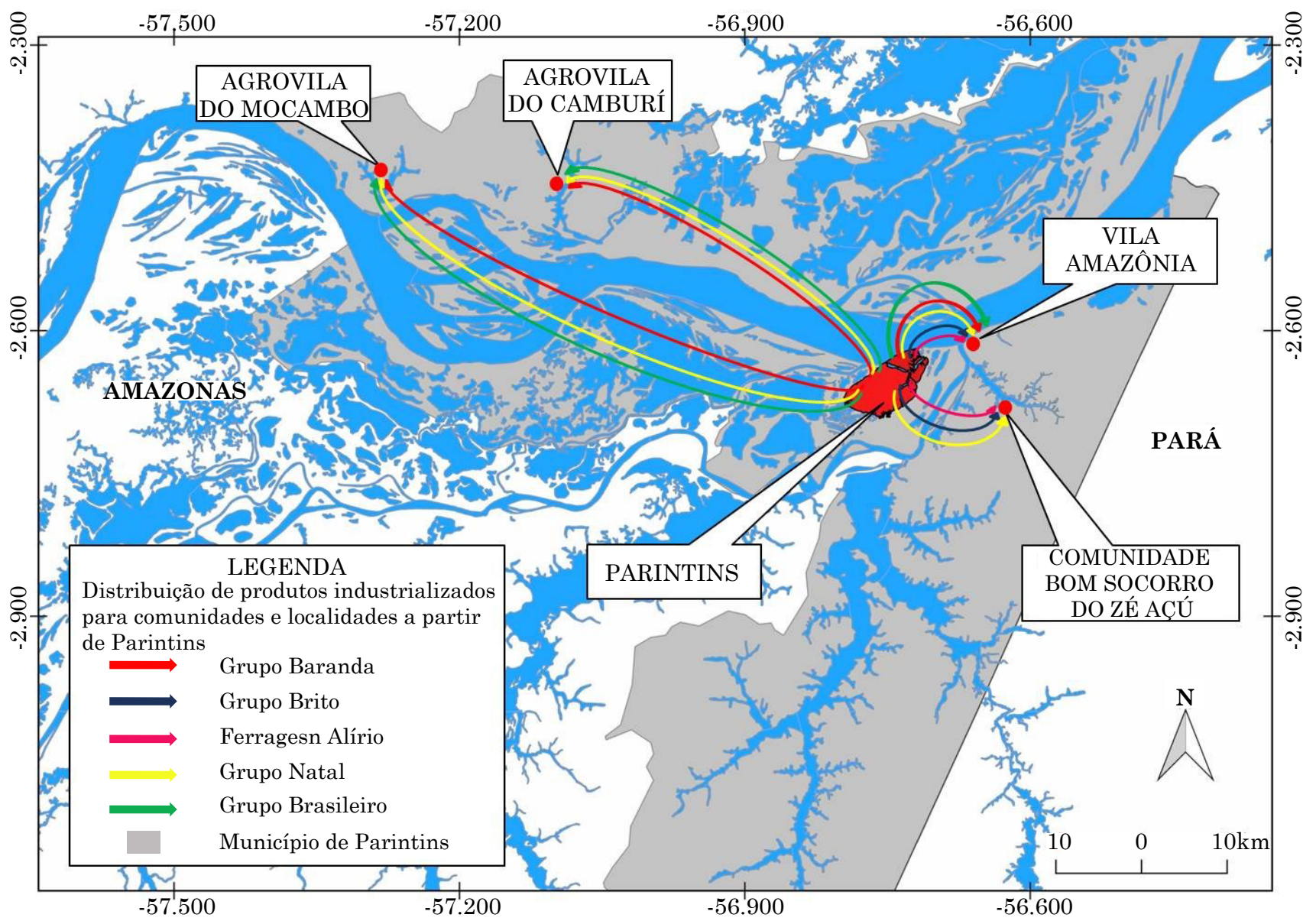

Fonte: Silva (2018)

Consolida-se uma hierarquia urbana na distribuição de produtos industrializados, corroborando a tese da urbanização extensiva, onde o trecho Manaus-Parintins é predominantemente articulado pelo STUF, e a partir da cidade, até atingir nódulos secundários depende das embarcações e redes de sujeitos pertencentes ao STUR, atingindo comunidades distantes posteriormente.

As balsas de Manaus abastecem a cidade (STUF), e embarcações diversas distribuem para os interiores (STUR). De acordo com Bartoli (2018), nessa fase do processo de distribuição, partindo de Parintins, os sistemas territoriais se complementam, interpenetram ou se sobrepõem, principalmente por parte do STUF, que utiliza os saberes - principalmente relacionados à navegação dos rios - próprios do STUR e da economia popular - como meio de distribuição de produtos industrializados, se revelando como articuladores da sub-região.

É através dessa influência que as empresas comerciais articulam escalas para manutenção de suas 
territorialidades, justapondo seus territórios de influência na sub-região. A rede urbana que se estabelece é resultado de estratégias de dominação de mercado, traçadas pelas empresas a partir de Parintins.

$\mathrm{Na}$ análise do mapa 2 (Figura3) fica claro que as atividades das empresas comerciais ultrapassam os limites do estado do Amazonas, avançando sobre o oeste paraense formando a rede de influência enquanto cidade média. Ultrapassam ainda a hierarquia estabelecida pelo Regic (IBGE, 2007), abrangendo uma sub-região de influência mais ramificada e de maior abrangência espacial.

Figura 3 - Rede urbana formada pela comercialização atacadista de Parintins para municípios da sub-região e oeste paraense.

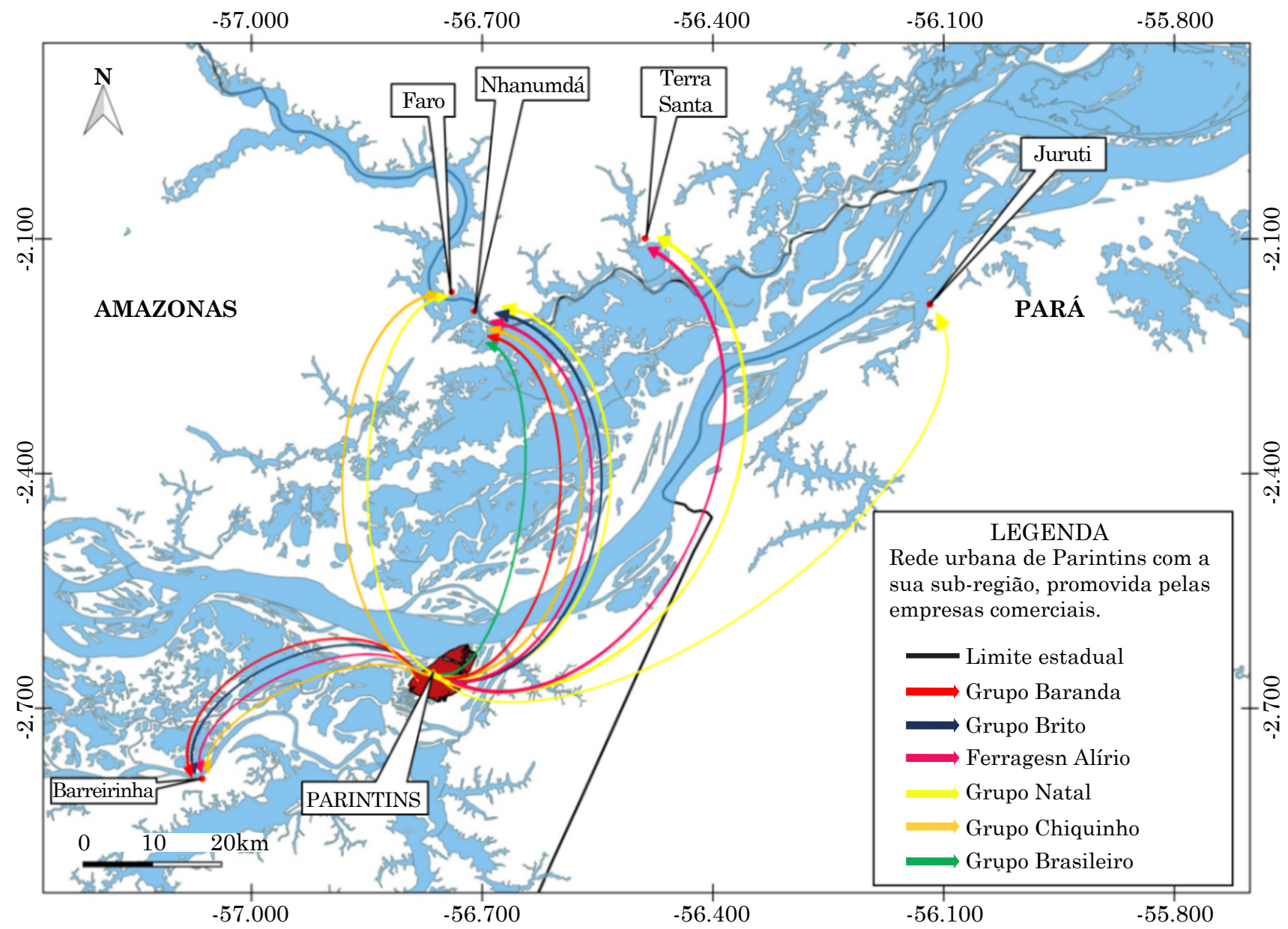

Fonte: Silva (2018).

Os fluxos representados no mapa 2 (Figura 3) são primordialmente compostos por itens da construção civil, gêneros alimentícios, gás de cozinha, combustíveis e água mineral ${ }^{5}$. Barreirinha e Nhamundá (AM), assim como Faro, Terra Santa e Juruti (PA), são pequenas cidades com baixa complexidade econômica e comercial

$5 \quad$ Essas mercadorias foram citadas pelas empresas de maneira geral como as mais vendidas por cada uma delas, reservando-se estas a não especificar quais cidades consomem em maior quantidade cada um desses produtos. que compõem a rede urbana de Parintins, tendo forte dependência em relação ao fornecimento de produtos industrializados e de serviços. Embora a cidade de Santarém possua complexidade superior de distribuição de bens e oferta de serviços, Parintins ainda assim disputa pequenos centros sob seu poder de influência direta.

Nessas pequenas cidades locais do entorno, existem apenas estabelecimentos comerciais mais "generalistas", que vendem de tudo: alimentos, eletrodomésticos, até materiais de construção, adquiridos via Parintins, mas transportados pela enorme quantidade de embarcações de madeira pertencentes a populares residentes nas 
cidades, que são os principais articuladores do STUR. Algumas comunidades mais próximas e de fácil conexão fluvial (inclusive na vazante dos rios), também possuem pequenos comércios desse tipo, funcionando como nós secundários de distribuição para comunidades menores e mais longínquas (BARTOLI, 2018a).

Quanto aos aspectos do espaço intraurbano, o Capital Mercantil se influencia na morfologia da cidade para suporte das suas práticas espaciais, cuja disposição dos vários portos privados do STUF demonstra estratégias de controle e do poder de configurar espaços. Durante as últimas duas décadas, as empresas mercantis expandiram investimentos para bairros populares originados por ocupações irregulares. São zonas de expansão urbana onde o comércio é crescente. A própria presença das lojas de materiais de construção (ferragens) nessas áreas se deve à lenta substituição das moradias de madeira por alvenaria, através do processo de autoconstrução pelos moradores. Investem ainda em postos de combustíveis, pontos de distribuição de água mineral e gás de cozinha e filiais, incentivados pelo consumo nas áreas de crescente expansão de bairros periféricos desde os anos 1990, obtendo pontos estratégicos.

Dos espaços onde as empresas comerciais atuam, as "beiras de rio" talvez sejam os locais que mais resultam impactos pelas atividades, devido aos conflitos que o processo envolve. São locais que ganham novos significados, em que até a década de 1980 se estabeleciam primordialmente práticas de uso das populações locais, como pescadores, ribeirinhos e moradores que compõem o STUR, utilizando margens para atracação de barcos, bajáras, canoas, rabetas e outros tipos de embarcações.

A expansão da cidade enquanto centro distribuidor de mercadorias na sub-região gera disputas por espaços para atracação de embarcações em diversos pontos (BARTOLI, 2018b). São beiras de rio que apresentam fluxos intensos de embarcações, gerando constantes disputas por acessos. Tais locais onde esses processos são mais incidentes estão na margem do Rio Amazonas, conhecida localmente como "frente da cidade" (centro e bairros do entorno) e às margens da Lagoa da Francesa (BARTOLI, 2018b). O centro é uma área com forte presença do comércio, onde está concentrada a maior parte das instituições bancárias, administrativas e o terminal hidroviário da cidade. Concentra portos particulares, um Terminal Flutuante e poucos acessos ainda públicos, propiciando constantes fluxos de embarcações, pessoas e mercadorias.

A maioria das empresas comerciais estudadas teve suas origens nesta parte da cidade e a partir daí começaram sua expansão para áreas como a Lagoa da Francesa, local onde ocorre fluxo intenso de embarcações no período das cheias dos rios, sendo uma nova centralidade de Parintins. O resultado desse fator foi o crescimento no número de empreendimentos de comércio implantados na área. Porém, existe determinada época do ano em que a sazonalidade dos rios também interfere na dinâmica do local. Com a vazante o fluxo de embarcações reduz praticamente a zero, pois o que resta no local é apenas um filete de água que impossibilita a navegação até mesmo de pequenas canoas. Devido a esta condição, as embarcações que antes ali circulavam passam a utilizar os portos particulares ou pequenas faixas de terra ainda não privatizadas, na "frente da cidade" às margens do Rio Amazonas.

Um desses portos particulares tem extrema importância para a navegação da região. Localizado às margens do Rio Amazonas o "porto do Dodó Carvalho" como é conhecido localmente, se torna ponto para atracação de balsas de ferro de diversas empresas da cidade que não possuem portos privados.

\section{CONSIDERAÇÕES FINAIS}

A expansão das atividades do Capital Mercantil em Parintins vem reforçando características relativas ao que Bartoli (2017) denominou como Sistema Territorial Urbano-Fluvial (STUF), com aumento da capacidade dessa rede de sujeitos em criar fluxos compondo a rede urbana sub-regional elevando o grau de importância de Parintins para sua rede urbana. Seja pelo uso de balsas que conferem maior poder concorrencial frente às demais empresas, ou na capacidade de moldar o espaço intraurbano, as dinâmicas que o Capital Mercantil imprime são fortalecidas pela diversidade de atividades de empreendimentos comerciais como lojas, postos de combustíveis, supermercados entre outros.

As escalas de atuação das empresas se valem dos sistemas territoriais para sua efetivação. O STUF realiza os fluxos com a capital Manaus e posteriormente dependendo do STUR para distribuição aos interiores. Nós urbanos secundários são parte da hierarquia intramunicipal, cumprindo função de distribuição de produtos a comunidades mais longínquas.

Assim, as empresas comerciais estudadas são mediadoras nas relações de Parintins com a Sub-região, contribuindo para que a cidade aumente o grau de centralidade na rede urbana quanto à oferta de bens industrializados. 


\section{REFERÊNCIAS}

AMAZONAS. [Constituição (1989)]. Constituiзго do Estado do Amazonas. Versão atualizada até a Emenda Constitucional n ${ }^{\circ} 96$ de 24.03.2017. Manaus: Assembleia Legislativa do Estado do Amazonas, 2017.

BARTOLI, E. O retorno ao territyrio a partir da cidade: sistemas territoriais urbano-ribeirinhos em Parintins (AM). 2017. Tese (Doutorado em Geografia) - Faculdade de Ciências e Tecnologia, Universidade Estadual Paulista, Presidente Prudente, 2017.

BARTOLI, E. Cidades na Amazônia, sistemas territoriais e a rede urbana. Mercator, Fortaleza, v. 17, p. 1-16, 2018 a.

BARTOLI, E. Entre o urbano e o ribeirinho: territorialidades navegantes e sistemas territoriais em Parintins (AM). Espaso Aberto, Rio de Janeiro, v. 8, n. 2, p. 169-185, 2018b.BRESSER-PEREIRA, L. C. Seis interpretações sobre o Brasil. Revista de Cikncias Sociais, Rio de Janeiro, v. 25, n. 3, p. 269-306, 1982.

BRESSER-PEREIRA, L. C. De volta ao capital mercantil. In: D'INCAO, M. A. Histyria e ideal: ensaios sobre Caio PradoJr. São Paulo: Brasiliense, 1989. p. 279-297.

CANO, W. Reflexões sobre o papel do capital mercantil na questão regional e urbana do Brasil. IE/UNICAMP, Campinas. n. 177, p. 1-22, 2010.

CORRÊA, R. L. Redes geográficas: reflexões sobre um tema persistente. Revista Cidades, São Paulo, v. 9, n. 16, p. 199-218, 2012.

CORRÊA, R. L. Trajetyrias geogrøficas. Rio de Janeiro: Bertrand Brasil, 1997.

HARVEY, D. A produção Capitalista do Espaço. São Paulo: Annablume, Coleção Geografia e Adjacências), 2005. 252p.
INSTITUTO BRASILEIRO DE GEOGRAFIA E ESTATÍSTICA (IBGE). Regiões de Influência das Cidades (2007). Rio de Janeiro: IBGE, 2008.

MONTE-MÓR, R. L. M. Urbanização extensiva e lógicas de povoamento: um olhar ambiental. In: SANTOS, M. et al. (org.). Territyrio, globalizaзro e fragmenтазго. São Paulo: Hucitec, 1994. p. 169-181.

MONTE-MÓR, R. L. M. Urbanização extensiva e novas fronteiras urbanas no Brasil. In: NETO, E. R.; BÓGUS, C. M. (org.). Saъde nos aglomerados urbanos: uma visão integrada. Brasília, DF: Organização PanAmericana da Saúde, 2003. p. 79-95.

OLIVEIRA, J. A.; SCHOR, T. Manaus: transformações e permanências, do forte a metrópole regional. In: CASTRO, E. (org.). Gidades na floresta. São Paulo: Annablume, 2009. p. 41-98.

OLIVEIRA, J. A.; SCHOR, T. Urbanização na Amazônia: o local e o global. In: VAL, A. L.; SANTOS, G. M. (org.). Caderno de debates. Manaus: Inpa, 2010. p. 147-189.

SCHOR, T. Cities, rivers and urban network in the Brazilian Amazon. Brazilian Geographical Journal, Ituiutaba, v. 5, n. 1, p. 258-276, 2014.

SCHOR, T.; OLIVEIRA, J. A. Reflexões metodológicas sobre o estudo da rede urbana no Amazonas e perspectivas para a análise das cidades na Amazônia brasileira. Acta Geogrofica, Boa Vista, v. 10, p. 15-30, 2011.

SILVA, F. L. F. Capital mercantil, transportes fluviais e a rede urbana sub-regional de Parintins AM. 2018. Monografia (Graduação em Licenciatura em Geografia) - Universidade do Estado do Amazonas, Parintins, 2018. 